\title{
Artificial intelligence in academic libraries: An environmental scan
}

\author{
Amanda Wheatley* and Sandy Hervieux* \\ McGill University, 3459 McTavish Street, Montreal, Quebec H3C 1Y7, Canada
}

\begin{abstract}
Due to the ever-increasing presence of artificial intelligence (AI), an environmental scan on academic libraries engagement with AI was conducted. The authors reviewed scholarly articles, university libraries' strategic plans, and library programming to determine if any reference to AI was being made and in what context. Top research universities in the United States and Canada were considered. The primary goal was to discover what role the librarian will play in an AI-dominant future, as well as how libraries are responding to this change. Findings indicated a lack of response or awareness to the current AI trend, though a small number of institutions were found to be participating in or creating their own AI hubs.
\end{abstract}

Keywords: Academic libraries, environmental scan, artificial intelligence, innovation in libraries, strategic planning, machine learning

\section{Introduction}

What is perhaps the library's best kept secret has been its slow uptake on automation and digital technologies. To the outside world, the library is a pioneer in the quest for innovation, from video collections to audio books and databases to makerspaces, the library is viewed as an agent of change. Those who criticize the library speak to the physical stacks and the social-economic divide, claiming that the information is online for all to seek [1,2]. It is not an argument that the library has failed to digitize, but rather an argument that raises the capitalistic aims of the information industry. Librarianship is quick to defend against this argument, but where the profession struggles is in admitting its faults in regards to digital progression. Historically, the library has been reluctant to change, often waiting for a particular technology to reach market saturation before reacting to a new trend. Once a patron has been readilyexposed to a technology across multiple venues, then the library will adopt its use.

Dominating the technology conversation for years has been the growth of artificial intelligence (AI) and machine learning (ML) in disciplines outside of the traditional sciences. Made popular by the works of science fiction, the capabilities of these two fields are only just beginning to unfold. This work is made more complicated by differing definitions of what AI is and what can be considered as AI. While there is an understanding that $\mathrm{AI}$ is a computer program designed to replicate human intelligence, the truth is that it is so much more. Everyday applications of AI are already well-integrated into society, through technology such as driverless cars, satellites, the Internet of Things, and perhaps most obviously, the Google search engine [3].

*E-mail: amanda.wheatley@mcgill.ca, sandy.hervieux@mcgill.ca. 
There are those who would like to confine the realm of AI to motion pictures and flights of fantasy. A vision of 2001: A Space Odyssey comes to mind and the malicious HAL 9000, the ship's AI, locking the bay doors [4]. This tendency to view AI as a villain is furthered in conversations today where workers are faced with the increasing reality of automated jobs. An Oxford University group looked at the future of the workforce in an AI-dominated world, seeking to identify which professions were most likely to become run by machines. Their results found that on a basis of 0 being a non-computerizable position and 1 being highly-computerizable, librarians ranked a 0.645 [5]. This unsettling reality should have awoken librarians, instead the profession reacted as it did to most technological revolutions - it waited. In fact, it is still waiting. In this paper, the authors explore how librarians and librarianship are reacting to the current increase in AI-related research and technology. By examining the top research institutions in the United States of America and Canada, the authors hope to identify whom, if anyone at all, is leading the charge toward integrating $\mathrm{AI}$ into the profession.

\section{Literature review}

Research connecting artificial intelligence (AI) to librarianship remains quite low. While the topic has been expanding exponentially in other fields, this has not been the case for all of the information sciences. Some research suggests that libraries should take a continuing education approach for AI, both from the perspective of its staff and its users [6]. Others are working on actively integrating AI into the virtual reference process through automated chatbots and a participatory culture that allows users to engage in the learning experience with the technology [7]. The use of agent technology was also explored in law libraries as a way to bridge information seeking behavior with the missions and values of libraries, citing digital libraries as a pioneer for this type of AI use. The areas in which law libraries saw benefits for agent technology include reference, information literacy instruction, and circulation [8]. However, most of the documentation on AI and libraries has appeared outside of scholarly research, notably in blog posts, newsletters, and magazine articles. These articles usually take an opinion-based or case study approach.

Associations and organizations that have already begun to acknowledge the role AI will play in the future of librarianship including the International Federation of Library Associations and Institutions (IFLA), the American Library Association (ALA), and the Canadian Federation of Library Associations (CFLA), to name a few. An IFLA Trend Report highlights the advances of AI and its connections to the semantic web and search, as well as improvements to translation and cloud-based computing [9]. In the ALA's Center for the Future of Libraries, AI projects with the potential to impact libraries have been cited, including chatbots, neural networks, education and more [10]. Whereas, a panel for CFLA warned of the risks associated with AI and the library, they cautioned that more librarians should be involved in this discussion, particularly on the topic of positioning, policies, and the creation of standards [11].

The absence of scholarly research on AI-related technologies in libraries is not to be unexpected. Libraries have suffered from issues on the adoption of digital technologies and a general resistance to change throughout the twentieth and twenty-first centuries. Library computerization had a slow upstart in the 1960s as automated internal processes started to emerge, but didn't fully take hold until the 1970s and 1980s [12]. In comparison, the National Information Standards Organization was founded in 1939 and was already engaging in automation standards by the 1960s [13]. The progression of industrial and office automation paved the way for libraries to adopt similar technology, yet this adoption was always years behind the current trends. 
Microforms were once seen as revolutionary in the 1980s, nearly twenty years after libraries began purchasing them in earnest. User adoption was originally slow, requiring libraries to adapt their outreach approach. Results on innovative approaches to microform acceptance indicated early on that users much preferred the immediate access to documents through which the medium afforded [14]. Microform and database-centric computers at the library eventually gave way to the Internet and, of course, the Google search engine. Much like the fear and paranoia surrounding AI now, librarians were convinced that these new digital developments would replace their jobs.

This fear of being dispensable is further tracked in the literature regarding libraries and digital technology. A study on the librarians at Tehran University found that ambiguity was a major source of resistance to technological change, combined with an uncertainty toward institutional change derived from said technology [15]. Research suggests that technological innovations can be successfully adopted when the approach makes clear connections to the intended benefits, as well as a positive influence from the society surrounding the technology [16]. When the messaging regarding AI propels the idea of job loss, machine dominance, and overall hopelessness, it is only natural that the environment would feel reluctant to include the technology. Possible suggestions for improving this type of resistance include linking new technologies to strategic plans and goals for the organization, communicating new change efforts, and frequent engagement of staff toward the new technology [17].

\section{Methodology}

The authors evaluated twenty-five universities and their libraries to determine the prevalence of collaborations surrounding artificial intelligence. The sample includes the fifteen Canadian universities part of the U15, a group of the most research-intensive universities in the country [18]. The American universities were selected from the Times Higher Education List and highlights some of the leading universities in the United States [19]. Although the University of Rhode Island and the University of Oklahoma were not part of the original sample, the authors decided to add them as outliers because the original sample provided very few instances of artificial intelligence and those universities offered applicable case studies for AI in academic libraries. Since the initial data collection took place in April 2019, the authors evaluated the websites again in July 2019 to ensure relevant updates would be included. The environmental scan is not intended as an exhaustive study on the presence of artificial intelligence in libraries, but rather it attempts to show a representative picture of $\mathrm{AI}$ in research-focused academic libraries. Table 1 outlines the universities that are part of the sample.

The authors used the searches imbedded in the university and library websites to search for the following keywords: artificial intelligence, machine learning, deep learning, AI hub. They also consulted the library's strategic plans or vision and mission statements, research and subject guides, lists of programming and events, as well as official partnerships to identify if artificial intelligence had any presence within the library. When evaluating subject guides, the authors looked for individual guides on artificial intelligence; guides that only mentioned the technology or had a short section dedicated to it were not included in the results. A similar approach was used to evaluate the university websites. The authors searched for the same keywords and also looked for AI hubs, courses on artificial intelligence and made note of significant researchers in the field. Notable researchers were defined as faculty members who had significant experience and contributions in the field of artificial intelligence, such as award and grants winners, as well as researchers in charge of AI hubs. Sessional lecturers were not included in the sample. The authors chose to include hubs with a focus on artificial intelligence as a whole and not specialized AI hubs that focus on specific areas such as business, medicine or law. The aim was to identify 
Table 1

University sample

\begin{tabular}{cc}
\hline Canadian Universities & American Universities \\
\hline University of Alberta & Stanford University \\
University of British Columbia & Massachusetts Institute of Technology \\
University of Calgary & California Institute of Technology \\
Dalhousie University & Harvard University \\
Université Laval & Princeton University \\
University of Manitoba & Yale University \\
McGill University & University of Chicago \\
McMaster University & John Hopkins University \\
Université de Montréal & University of Pennsylvania \\
University of Ottawa & University of California, Berkeley \\
Queen's University & University of Rhode Island* \\
University of Saskatchewan & University of Oklahoma* \\
University of Toronto & \\
University of Waterloo & \\
Western University & \\
\hline
\end{tabular}

*The University of Rhode Island and the University of Oklahoma were added after the initial scan due to their large presence in the AI conversation.

potential partners for the library and the authors decided that specialized hubs would not be as conducive to partnership as those with a more general focus could be.

The results for each institution were entered in an evaluation table that outlined the criteria mentioned above. The evaluation table can be seen in appendix A at the end of this article. Once the environmental scan was completed, the authors compiled the results in a comparison matrix using Google Sheets.

\section{Results}

\subsection{Artificial intelligence in strategic planning}

The most surprising result from the environmental scan was the discovery that no university or university library mentions artificial intelligence in their strategic plan. While most plans were fairly recent, there are no initiatives to address the rise of artificial intelligence technology. Most university libraries do include statements about digital innovation and initiatives, and some, such as the University of California Berkeley, specifically address areas such as digital scholarship. It is also interesting to note that some universities and their libraries do not have strategic plans or mission statements publicly-accessible on their websites. Mentions of artificial intelligence could be found within more dedicated research plans for some of the institutions.

\subsection{AI presence in universities}

While there are no strategic intentions related to artificial intelligence in libraries, all universities have some level of engagement with AI. The most prominent examples are course offerings in artificial intelligence. Not surprisingly, artificial intelligence is heavily present in departments and schools of computer science and mathematics. Certain courses are also being offered to teach the implications of 
Table 2

AI presence in sampled universities

\begin{tabular}{|c|c|c|c|}
\hline University name & Courses taught & AI Hub & Notable researcher \\
\hline University of Alberta & $\mathrm{x}$ & $\mathrm{x}$ & $\mathrm{x}$ \\
\hline University of British Columbia & $\mathrm{x}$ & & $\mathrm{x}$ \\
\hline University of Calgary & $\mathrm{x}$ & $\mathrm{x}$ & $\mathrm{x}$ \\
\hline Dalhousie University & $\mathrm{x}$ & $\mathrm{x}$ & $\mathrm{x}$ \\
\hline Université Laval & $\mathrm{x}$ & $\mathrm{x}$ & $\mathrm{x}$ \\
\hline University of Manitoba & $\mathrm{x}$ & & \\
\hline McGill University & $\mathrm{x}$ & $\mathrm{x}$ & $\mathrm{x}$ \\
\hline McMaster University & $\mathrm{x}$ & $\mathrm{x}$ & $\mathrm{x}$ \\
\hline Université de Montréal & $\mathrm{x}$ & $\mathrm{x}$ & $\mathrm{x}$ \\
\hline University of Ottawa & $\mathrm{x}$ & $\mathrm{x}$ & $\mathrm{x}$ \\
\hline Queen’s University & $\mathrm{x}$ & $\mathrm{x}$ & $\mathrm{x}$ \\
\hline University of Saskatchewan & $\mathrm{x}$ & $\mathrm{x}$ & $\mathrm{x}$ \\
\hline University of Toronto & $\mathrm{x}$ & $\mathrm{x}$ & $\mathrm{x}$ \\
\hline University of Waterloo & $\mathrm{x}$ & $\mathrm{x}$ & $\mathrm{x}$ \\
\hline Western University & $\mathrm{x}$ & & $\mathrm{x}$ \\
\hline Stanford University & $\mathrm{x}$ & $\mathrm{x}$ & \\
\hline Massachusetts Institute of Technology & $\mathrm{x}$ & $\mathrm{x}$ & $\mathrm{x}$ \\
\hline California Institute of Technology & $\mathrm{x}$ & $\mathrm{x}$ & \\
\hline Harvard University & $\mathrm{x}$ & $\mathrm{x}$ & \\
\hline Princeton University & $\mathrm{x}$ & $\mathrm{x}$ & $\mathrm{x}$ \\
\hline Yale University & $\mathrm{x}$ & $\mathrm{x}$ & \\
\hline University of Chicago & $\mathrm{x}$ & $\mathrm{x}$ & $\mathrm{x}$ \\
\hline Johns Hopkins University & $\mathrm{x}$ & & \\
\hline University of Pennsylvania & $\mathrm{x}$ & & \\
\hline University of California Berkeley & $\mathrm{x}$ & $\mathrm{x}$ & \\
\hline University of Oklahoma & $\mathrm{x}$ & $\mathrm{x}$ & $\mathrm{x}$ \\
\hline University of Rhode Island & $\mathrm{x}$ & $\mathrm{x}$ & \\
\hline
\end{tabular}

AI in certain fields such as law, business, and medicine. All universities included in the sample offer courses on artificial intelligence.

In order to supplement their course offerings and further research, several universities house artificial intelligence hubs or centers. The authors discovered that $81.5 \%$ of universities sampled have an identifiable research hub that focuses on artificial intelligence. As previously mentioned, this percentage does not include subject specific hubs focusing on the impact that AI is having on niche subject areas with limited transdisciplinary applications (for example, an automotive AI hub).

The authors also evaluated the presence of notable faculty members and researchers who focus on artificial intelligence in universities. Only $66.7 \%$ of sampled institutions count notable researchers in the field of AI and related disciplines such as machine and deep learning. Table 2 highlights the presence of $\mathrm{AI}$ in the sampled research universities.

\subsection{AI in library programming and documentation}

Given the level of university involvement in artificial intelligence, one would assume that libraries are deeply involved in this topic, however, the environmental scan depicts a very different picture. Figure 1 below shows the percentage of libraries that offer programming related to artificial intelligence. 


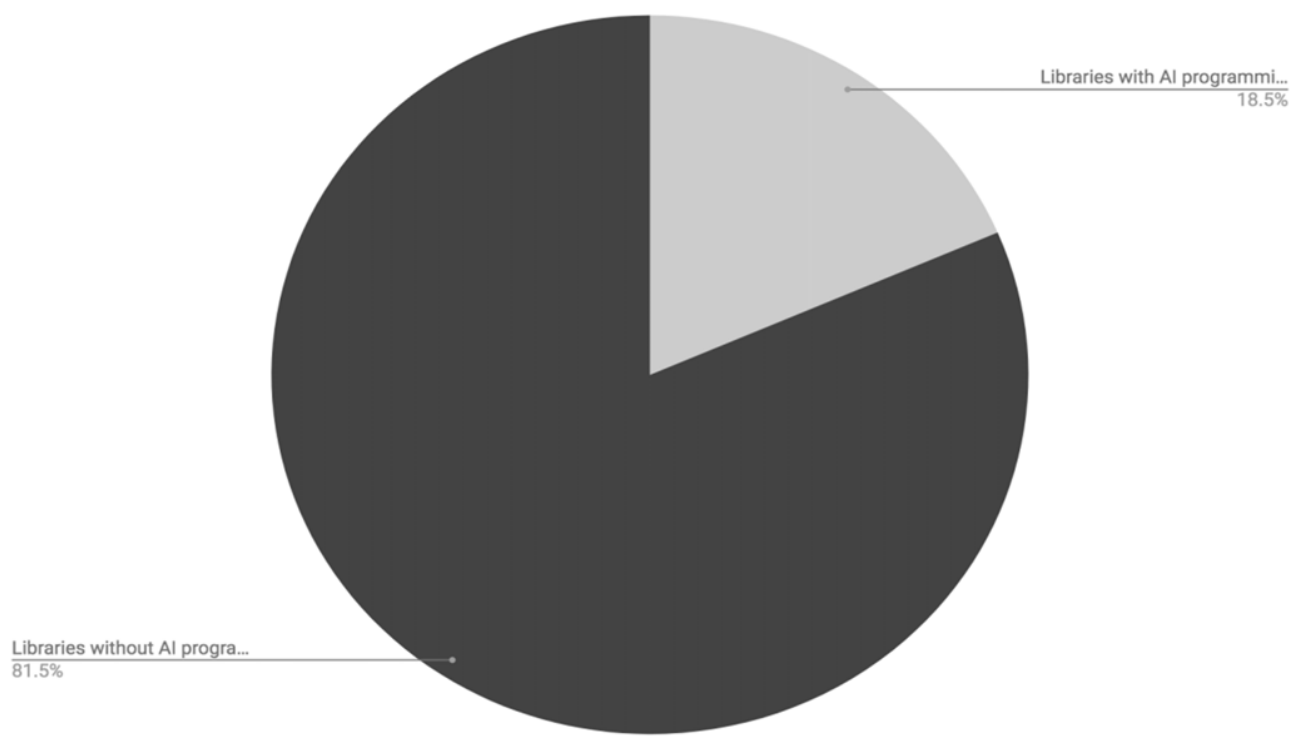

Fig 1. Libraries and artificial intelligence programming.

Only five university libraries out of the twenty-seven sampled offer programming and services related to artificial intelligence. The most common offerings are workshops that focus on the technological aspects of AI such as arduino kits, coding, and robotics. Other initiatives of interest include offering services related to data visualization and 3D printing. While these examples focus on the more technological opportunities awarded by artificial intelligence, some libraries, such as the Stanford University Library, host events of a more academic nature, such as conferences.

The Stanford University Library also has an AI Studio run by volunteer staff that aims to "make their collections more discoverable and analyzable for researchers" [20]. It is an internal initiative and is not yet open to students or the wider university community.

In terms of documentation, only one university library has created a specialized guide on AI. It is interesting to note that although the University of Calgary had the fewest documented courses available on artificial intelligence, it is the only library with a subject guide on this topic. Although the University of Oklahoma Library does not have a guide on AI, they have created a repository of research projects that focus on artificial intelligence.

\subsection{AI collaborations between the library and other units}

Very few university libraries collaborate with other units within their institutions on artificial intelligence initiatives. In 2006, the MIT Library partnered with the MIT Computer Science and Artificial Intelligence Lab on a grant-funded project to create search engines that use AI [21]. While this collaboration resulted in several online tools that are still available today, no other partnerships have been created to work on the uses of artificial intelligence in the library. More recent initiatives include the University of Oklahoma's Digital Skills Hub, which offers workshops and events in partnership with other university departments to make students aware of emerging technologies, including AI [22]. The library is also part of the Alexa in Education program that is offered at the University of Oklahoma. This program aims to encourage students to create new Alexa skills to support their university experience [23]. The University 
of Rhode Island Library recently created its Artificial Intelligence Lab, which is not only supported by librarians and library staff, but also by professors from different departments such as philosophy and computer science. Their lab also hosts campus-wide events about AI and includes technology materials for use and loan [24].

\section{Discussion}

Startlingly few academic libraries have begun to engage in official projects or labs centered on artificial intelligence. The number of partnerships recorded, while not entirely surprising, was extremely low. This in and of itself would not be as big of an issue except for the fact that there are a high number of AI hubs on these campuses with the potential to collaborate. A notable instance was the University of Waterloo's Centre for Pattern Analysis and Machine Intelligence, a student research group with projects involving semantic speech decoding for search engines and information repositories conducted through AI [25]. With research projects such as this, there is tremendous potential for the library to be involved. The CFLA's recognition that librarians should be part of the AI conversation could have seamless integration with hubs such as Waterloo's in the future, but first it will require libraries to become active members in the conversation [26].

Rather than take a responsive or reactive approach, libraries can initiate these conversations in their strategic planning. The absence of AI within the noted university libraries' planning was not a surprise. Most of these documents were built around vague references to emerging technologies or digital scholarship, if those were even mentioned at all. The authors acknowledge the intention by administration to avoid labelling specific technologies, however, artificial intelligence is not one specific technology. As researchers have already noted, clear communication and identification of these digital developments can help increase user adoption and staff acceptance [27].

Another area where libraries could be seen to improve is in the outreach and instruction of AI-related topics at their institutions. Very few libraries offer programming or other initiatives on the topic, some of which include speaker series and workshops. The University of Toronto is in the process of launching their first ever year-long challenge to learn and have discussions on artificial intelligence as part of a joint effort with the library [28].

It is also interesting to note that some of the university libraries that have engaged with AI are smaller in size. One could easily assume that larger academic libraries who receive more funding would be at the center of conversations surrounding new technologies and AI; however, the authors found the opposite to be true. While Stanford and MIT have engaged with AI, the University of Oklahoma and the University of Rhode Island have emerged as the leaders in involvement with AI. This could possibly be related to a more dedicated focus among faculty and less need to spread out resources across a massive student body with widely varying research interests. Additionally, small institutions may not be as bound to the bureaucratic process, thus giving them more flexibility to pursue new initiatives.

Given that AI will certainly affect the way individuals search for information, a natural fit for the library would be to position itself at the forefront of AI instruction. Libraries have always prided themselves on their involvement in information literacy, however, almost no initiatives have focused on educating patrons on AI. Whether this is voice assistants or search algorithms managed by AI, it is clear that this field will have a deep impact on the search process. There have also been no initiatives to update current library standards, such as the Framework for Information Literacy in Higher Education, in relation to concerns brought on by artificial intelligence including bias in search results and ethics considerations [29]. 


\section{Conclusion}

The current state of artificial intelligence in academic libraries has proven to be nearly non-existent. The lack of research poses a gaping hole in the literature that will need to be filled if libraries expect to engage in the AI conversation. The libraries that are already active and creating opportunities for engagement have set the pace for future work to come. As ALA has already begun tracking applicable technologies, it is only a matter of time before these become mainstream in the academic research process. Even though some associations have begun urging library involvement in AI, the uptake has been slow. Some academic libraries have engaged with artificial intelligence, most notably Stanford, MIT, the University of Oklahoma, and the University of Rhode Island, but work still needs to be done in librarianship in order to make true advances in the application of $\mathrm{AI}$ in libraries.

For those looking to establish more research on AI, the University of Oklahoma has created the Projects in Artificial Intelligence Registry (PAIR). This venture hopes to connect those conducting research and move the AI conversation more directly into libraries [30]. The authors hope to see the profession engage in artificial intelligence and work to become thought leaders in the field. The AI revolution is not on the horizon, it is already here and libraries need to make peace with this fact and begin the process of co-existence.

\section{Appendix: Evaluation criteria document}

\begin{tabular}{|l|l|}
\hline Date Reviewed & \\
\hline University & \\
\hline Link & \\
\hline Strategic Plan & \\
\hline Programming & \\
\hline $\begin{array}{l}\text { Research/subject } \\
\text { guide }\end{array}$ & \\
\hline $\begin{array}{l}\text { Presence within } \\
\text { University }\end{array}$ & \\
\hline Links to Library & \\
\hline Al Hubs & \\
\hline Notable Researchers & \\
\hline & \\
\hline Notes: & \\
\hline
\end{tabular}




\section{References}

[1] S. Denning, Do we need Libraries?, Forbes [Internet]. (2015). Available at: https://www.forbes.com/sites/stevedenning/ 2015/04/28/do-we-need-libraries/\#3cae49496cd7, accessed August 28, 2019.

[2] S. Berman, Classism in the stacks: Libraries and poverty, Journal of Information Ethics (2007), 103-110, https://search.proquest.com/openview/5d2383c5ab79e11 cea77e2d32fc9ea6c/1?pq-origsite=gscholar\&cbl=2035668, accessed August 28, 2019.

[3] M.A. Boden, Artificial Intelligence: A Very Short Introduction [Internet]. [Oxford]: Oxford University Press, 2018 (Very short introductions, 575). Available from: http://dx.doi.org/10.1093/actrade/9780199602919.001.0001, accessed August 28, 2019.

[4] S. Kubrick, 2001: A Space Odyssey, Metro-Goldwyn-Mayer, 1968.

[5] C.B. Frey and M.A. Osborne, The future of employment: How susceptible are jobs to computerization?, Technological Forecasting and Social Change (2017), 254-80.

[6] K. Arlitsch and B. Newell, Thriving in the age of accelerations: A brief look at the societal effects of artificial intelligence and the opportunities for libraries, Journal of Library Administration 57(7) (2017), 789-798.

[7] F. Yao, C. Zhang and W. Chen, Smart talking robot Xiaotu: Participatory library service based on artificial intelligence, Library Hi Tech 33(2) (2015), 245-260.

[8] N.B. Talley, Imagining the use of intelligent agents and artificial intelligence in academic law libraries, Law Library Journal 108(3) (2016), 383-401.

[9] IFLA Trend Report, Advances in Artificial Intelligence, available at: https://trends.ifla.org/literature-review/advances-inartificial-intelligence, accessed September 3, 2019.

[10] American Library Association, Tools, Publications \& Resources, Artificial Intelligence, 2019, available at: http://www.ala.org/tools/future/trends/artificialintelligence, accessed September 3, 2019.

[11] CFLA-FCAB, Artificial Intelligence and Intellectual Freedom: Key Policy Concerns for Canadian Libraries, Canadian Federation of Library Associations/Fédération canadienne des associations de bibliothèques (CFLA-FCAB) National Forum Paper. 2018, available at http://cfla-fcab.ca/wp-content/uploads/2018/07/CFLA-FCAB-2018-National-ForumPaper-final.pdf, accessed September 3, 2019.

[12] C.L. Borgman, From acting locally to thinking globally: A brief history of library automation, Library Quarterly 67(3) (1997), 215-249.

[13] What We Do, NISO, available at: https://www.niso.org/what-we-do, accessed September 3, 2019.

[14] M.P. Whitmore, An innovative approach to user acceptance of microforms, Journal of Academic Librarianship 9(2) (1983), 75.

[15] M. Nakhoda and S. Tajik, A survey of the factors influencing the resistance of the employees of university libraries to technological changes: Study of libraries of Tehran University, Library Management, (Bradford) 38(8/9) (2017), 528-546.

[16] S.G. Weiner, Resistance to change in libraries: Application of communication theories, Portal: Libraries and the Academy 3(1) (2003), 69-78.

[17] H.F. Cervone, Overcoming resistance to change in digital library projects, OCLC System and Services (Bradford) 27(2) (2011), 95-98.

[18] U15: Our members, U15 Group of Canadian Research Universities, available at: http://u15.ca/our-members, accessed September 3, 2019.

[19] Best Universities in the United States, Times Higher Education, 2019, available at: https://www.timeshighereducation.com/ student/best-universities/best-universities-united-states, accessed September 3, 2019.

[20] Stanford Libraries. SUL AI Studio, available at: https://library.stanford.edu/projects/artificial-intelligence.sul-ai-studio, accessed September 7, 2019.

[21] H. Denny, MIT awarded \$1.5 million for research on new search technologies for digital libraries, MIT Libraries News, 2006. Available at: https://libraries.mit.edu/news/mit-awarded-15-million-for-research-on-new-search-technologies-fordigital-libraries/333/, accessed September 7, 2019.

[22] N. Spears, OU's Digital Skills Hub to promote importance of technological literacy in spring kickoff, $O U$ Daily, Jan 29, 2019. Available at: http://www.oudaily.com/news/ou-s-digital-skills-hub-to-Promote-importance-oftechnological/article_ca41a1f8-2413-11e9-9346-735f760c835f.html, accessed September 7, 2019.

[23] B. Vacherot, University of Oklahoma Expands Student Engagement with Alexa Skills, Alexa Blog, 2017. Available at: https://developer.amazon.com/blogs/alexa/post/b9411ff3-02c4-47d5-acea-062c0bf0fd63/university-of-oklahomaexpands-student-engagement-with-alexa-skills, accessed September 7, 2019. 
[24] D. Lavallee, URI opens first artificial intelligence lab housed in a university library, URI Today, September 25, 2018. Available at: https://today.uri.edu/news/uri-opens-first-artificial-intelligence-lab-housed-in-a-university-library/, accessed September 7, 2019.

[25] University of Waterloo. Research Areas, Centre for Pattern Analysis \& Machine Intelligence, 2014. Available at: https://uwaterloo.ca/centre-pattern-analysis-machine-intelligence/research-areas, accessed September 7, 2019.

[26] CFLA-FCAB, Artificial Intelligence and Intellectual Freedom: Key Policy Concerns for Canadian Libraries, Canadian Federation of Library Associations/Federation canadienne des associations de bibliothèques (CFLA-FCAB) National Forum Paper. 2018, available at http://cfla-fcab.ca/wp-content/uploads/2018/07/CFLA-FCAB-2018-National-ForumPaper-final.pdf, accessed September 3, 2019.

[27] S.G. Weiner, Resistance to change in libraries: Application of communication theories, Portal: Libraries and the Academy 3(1) (2003), 69-78.

[28] University of Toronto, The 99 AI Challenge, University of Toronto Libraries, 2019. Available at: https://onesearch.library.utoronto.ca/ai-challenge, accessed September 7, 2019.

[29] Framework for Information Literacy for Higher Education, Association of College \& Research Libraries (ACRL), 2015. Available at: http://www.ala.org/acrl/standards/ilframework, accessed September 7, 2019.

[30] C. Grant and T. Camp, Scaling artificial intelligence in libraries via a national project registry. Intellectual Crossroads of the University, 2018. Available at: https://www.cni.org/wp-content/uploads/2019/01/CNI_Scaling_Grant.pdf, accessed September 7, 2019. 